\title{
III
}

\section{THE PROSTATIC LEUCOCYTE IN RELA- TION TO THE DIAGNOSIS AND TREATMENT OF PROSTATITIS}

By I. W. LAZARUS, M.B., B.S.(Lond.), M.R.C.S., L.R.C.P., Assistant Medical Officer, The Whitechapel (L.C.C.) Clinic, London, E. I

MosT observers agree that when prostatic secretions contain more than five or six leucocytes per one-twelfth objective field, prostatitis can be diagnosed. Mitchell and Von Lackum write, "To establish a diagnosis of prostatitis of clinical significance the fluid expressed must contain pus cells." Wolbarst says, " Prostatic secretion showing more than four or five leucocytes in one-sixth objective field suggests chronic prostatitis."

This paper gives a critical review of the evidence which justifies a diagnosis of prostatitis of clinical significance, and deals with the efficacy of its present-day treatment. Although Luys says " glandular prostatitis is asymptomatic," and Parnell writes that "glandular prostatitis was often asymptomatic and could not be diagnosed by palpation, but only detected by the microscope," in practice most workers assume that prostatitis of clinical significance includes asymptomatic and symptomatic cases. Nevertheless, the diagnosis is made quite apart from physical signs. Thus large, hard prostates, small soft prostates, irregular and nodular prostates, afford no definite indication as to the leucocyte content and are of minor importance as signs of prostatitis of clinical significance. The ultimate criterion is the leucocyte count.

In an attempt to criticise this assumption and the treatment based upon it, an investigation was made of 2 I2 patients who attended the L.C.C. (Whitechapel) Clinic during I93I. Of these, Ioo gave no history of gonorrhœa, nor had they ever had a discharge. Most of them were non-venereal " wind-up" cases, scabetics or syphilitics ; the second Ioo gave a history of gonorrhœa from one to fifteen years previously. The other I2 were gonorrhœal patients recently discharged as cured. They 


\section{BRITISH JOURNAL OF VENEREAL DISEASES}

had returned by request at six-weekly intervals for prostatic investigation.

Of the first Ioo patients all were asymptomatic (as regards the genito-urinary system). Examination of the prostate was performed, and the "prostatic beads" were investigated. The results were that 30 showed secretions containing between 5 and 40 leucocytes per field. Of these 30, II secretions contained 40 leucocytes per field. Of these II cases only 6 had abnormal prostates, which were irregular, nodular, larger or smaller, firmer or softer than normal.

Four specimens showed a leucocyte content of 20 cells. Of these 2 had clinically abnormal prostates.

Five specimens had a leucocyte content of ro cells; 2 of these prostates were clinically abnormal.

The remaining Io of the 30 cases showed secretions containing between 5 and 8 leucocytes per field. Three were clinically abnormal. Thus of 30 microscopically pathological cases, only I3 clinically abnormal prostates were found.

Assuming that a prostatic secretion with more than 5 leucocytes per field is abnormal, and that this abnormality constitutes a prostatitis of " clinical significance," then 30 per cent. of these Ioo symptomless cases were suffering from a prostatitis demanding treatment.

The second series of cases consisted of Ioo discharged gonorrhœal patients divided into two groups of asymptomatic and symptomatic cases.

\section{GRouP I.-ASYMPtomatic CASES}

Fifty-three patients were venereally asymptomatic and came for tests before marriage or with non-venereal symptoms. Of these 4I had pathological beads (between 8 and 40 cells per field), and 50 per cent. of them had over 20 cells per field. Nineteen only of these 4I cases had clinically abnormal prostates. Thus, 78 per cent. of these 53 asymptomatic cases, who, after efficient treatment, were discharged as cured, can be included among the cases of prostatitis " of clinical significance."

\section{Group 2.-Symptomatic CASES}

These were 47 of the Ioo cases of " cured " gonorrhœa who had returned with " gleet." 


\section{THE PROSTATIC LEUCOCYTE}

(a) Urethoscopy excluded the urethra as the active focus.

(b) Prostatic examination revealed the following facts. The secretions of 25 showed high leucocyte counts : only I8 prostates were clinically abnormal. Of the latter secretions only 9 showed pathological leucocyte counts. Of the 29 clinically normal prostates, I6 had a pathological leucocyte count.

The above analysis proves not only the lack of correlation between the clinical condition of the prostate and its leucocyte content, but also that symptomatic prostatitis (at least in 47 per cent. of the second group of cases) can and does exist, together with a normal leucocyte count. Many observers would not regard these patients as sufferers from prostatitis.

I have already quoted that in asymptomatic prostatitis the diagnosis rests on the abnormally high leucocyte count, but nowhere is it mentioned that a symptomatic prostatitis exists in the absence of an abnormal or high leucocyte count. Indeed, Von Lackum says, " the degree of clinical infection is graded by the number of pus cells present."

I deal now with the remaining I2 patients who were discharged as cured after rigid tests of cure extending over three consecutive weeks. Three prostatic smears contained only a few scattered leucocytes, and the cultures were negative. Patients were told to attend the Clinic every six weeks after they were discharged. Two of these cases, after the first six weeks, showed ro leucocytes per field in their prostatic beads.

Three cases showed between Io and 20 leucocytes per field at the end of the second six weeks.

Thus, 5 out of I 2 asymptomatic and clinically ured cases had pathological leucocyte counts.

In reviewing the analysis of these 2 I 2 cases, it is found that just as digital examination of the prostate affords no means of estimating the degree of leucocyte content, it can with equal justification be claimed that the leucocyte content affords no accurate basis for the estimation of the clinical condition of the prostate. Also we frequently note the lack of response in the leucocyte count during the progress of gonorrhœal metastatic lesions. Great importance is attached to the prostate (as well as to vesicles) as a focus in these metastatic cases. Clinical 


\section{BRITISH JOURNAL OF VENEREAL DISEASES}

examination of the prostate (where vesicles are not palpably involved) gives no reliable evidence as to its being a source of infectivity, and examination of the prostatic fluid leaves us equally uninformed. In large numbers of metastatic complications the prostatic leucocyte content is no greater than that observed in the asymptomatic prostates under treatment. Again, subsidence of the metastatic complication does not follow or precede a reduction of the leucocyte count in such manner as to leave no doubt as to the focal part played by the prostate. I have examined many cases in which acute metastatic complications were accompanied by moderate leucocyte counts, and where recovery from these lesions was accompanied by corresponding increased or diminished or stationary leucocyte counts. I do not say that treatment applied locally to the prostate or to the metastasis itself does not alleviate the clinical condition. Symptoms may subside, but not the prostatic leucocyte count. I contend that a factor or factors are present (either within or without the prostate) which are of greater importance than the prostatic leucocyte count.

Again it is difficult to reconcile clinical data gleaned from many asymptomatic patients, whose prostatic beads after months of regular massage are full of leucocytes, with the condition of gleety, rheumatic or otherwise symptomatic patients whose beads vary from month to month ; at first almost normal, later heavily laden with pus, and seldom showing two consecutive beads alike.

In most of the acute gonorrhœal cases at the London Hospital and the L.C.C. (Whitechapel) Clinic during the past three years, the urethral discharge had stopped and the urines (examined by the two-glass test) became clear about the end of the first month of irrigation. After urethroscopy had excluded active urethral lesions demanding local treatment, fluid expressed from the prostate almost always showed many leucocytes, and generally absence of the gonococcus. A diagnosis of prostatitis was assumed, and prostatic massage instituted. The exceptional cases of prostatitis with acute symptoms and signs (general and focal) were not actively treated, and therefore the leucocyte content of the prostatic secretion was unknown. Later examination of these " prostatic beads " showed numbers of leucocytes comparable to the numbers found in asymptomatic cases. These asympto- 


\section{THE PROSTATIC LEUCOCYTE}

matic cases of acute prostatitis, together with those who had to rest on account of symptoms, were given daily urethral irrigations of $\mathrm{KMNO}_{4}$ and prostatic massage twice weekly. After a month's treatment a second prostatic bead was examined. The leucocyte count might be higher, lower, or the same as the previous bead. There was nothing in the general condition of the patient or in the clinical condition of the prostate which could be correllated to the change in the leucocyte count. Usually the count was high-about 20 leucocytes per field being the average. Treatment was continued, and a third " bead" examined at the end of the second month of massage. The majority of these "beads" showed similar abnormal leucocyte counts. The patient was given anything up to a month's rest from all active treatment, but he was expected to refrain from alcohol, sexual excitement, condiments, and to abstain from the more active sports and exercise. On returning he was usually asymptomatic and his urine clear, and showed no change in the clinical condition of the prostate. The leucocyte content in the prostatic secretion showed no appreciable change in the majority of cases. At this point treatment was usually varied. Diathermy, massage of the prostate after the passage of large curved sounds, posterior urethral installations, etc., were tried. The leucocyte count showed transient changes but rarely was it maintained for long within the limits of normality. Finally the patients defaulted or the test of cure was completed in those whose prostatic secretion contained over Io leucocytes per field in three consecutive " beads" taken at weekly intervals. I may mention that in defence of the treatment it is argued that patients do not co-operate with the clinician; they drink, have coitus or are careless of dietetic rules. The answers to these aspersions are :-

(I) We have no reason to believe that most patients lie, and every reason to believe that they do not.

(2) Patients in the early stages do not progress if they break the rules.

(3) Patients do not get worse, on the contrary, many improve, in spite of breaking rules, unless patients lie when they tell us they drink, etc.

Many patients, including drinkers and the highly sexed, default. The conscientious, i.e., the intelligent patient, 


\section{BRITISH JOURNAL OF VENEREAL DISEASES}

continues and his co-operation is unquestionable. After a year or so of varied treatment and of hopes raised only to be vanquished, his misery is complete. He keeps the rules, he feels fit, yet he is told his " beads" are still bad. $\mathrm{He}$ cannot understand it, his morale breaks, and frequently he becomes neurasthenic. Ceasing to attend symptomless, he appears with cheerful regularity week after week with testicular discomfort, vague pains in the penis, peculiar feelings in the groins, and the like. $\mathrm{He}$ has, at last, justified himself; he does not now attend for nothing.

Nothing is more to be deplored than the attacks made upon prostates, merely because they harbour an abnormal number of leucocytes, not so much because the majority of these attacks are doomed to failure, but chiefly because of the demoralising and pernicious effects on clinically cured patients, who thus are subjected to over-treatment.

The above description, which represents the state of affairs with regard to such patients, suggests the problem : do the results of treatment, in asymptomatic cases, justify the assumptions upon which it is based ? I contend that they do not, and an attempt will now be made to reexamine the evidence upon which treatment is deemed necessary. The suggestions made in support of the contention that a high leucocyte-bearing prostate is of clinical significance may be classified thus :-

(I) That the prostate acts, or can act, as a focus of infection.

(2) That the prostate is responsible for local clinical exacerbation, e.g., gleet, backache, urinary symptoms, etc.

(3) The occurrence of consort infectivity.

(4) That a high leucocyte count may be a contributory ætiological factor in the production of the senile enlarged prostate.

(I) Little remains to be said about the first statement. No one has associated a high prostatic leucocyte count with lesions such as gastric or duodenal ulceration or cardiac disease. Regarding rheumatism as a metastatic lesion, I have tried to demonstrate that the leucocyte count bears little relation to the onset and clinical progress of such a condition.

(2) As to local clinical exacerbation the above analysis demonstrates the relative unimportance of the leucocyte in estimating the nature or degree of prostatic involve- 


\section{THE PROSTATIC LEUCOCYTE.}

ment. Thus, none of the 30 patients (non-venereal) who had pathological prostatic leucocyte counts had had any genito-urinary symptoms. Also the probability of a gleet in patients who have never had a discharge is remote.

Of the 53 asymptomatic gonorrhœa patients who returned with high prostatic leucocyte counts, none had had symptoms since their discharge. Again, of the 47 returned "gleet" cases where the "focus" was presumably in the prostate, 47 per cent. had normal leucocyte counts. Hence the focal significance in these cases must bear relation to a factor other than a high leucocyte count.

(3) The question of consort infectivity is important. Is it possible for an asymptomatic patient, harbouring, e.g., 20 leucocytes per field in his prostatic fluid, to infect his consort? Convincing evidence for or against this possibility is most difficult to obtain. Of the 30 nonvenereal patients who were asymptomatic and had high leucocyte counts, those who were married had no knowledge that their wives had complained of or been treated for a discharge.

(4) With regard to the fourth contention, it is said that counts of $I_{5}$ to 20 leucocytes are commonly found in elderly men, but that this is of no clinical significance, except that they may occur in candidates for prostatectomy.

Whatever the significance of these high leucocyte counts may be, the inefficacy of prostatic massage (which remains the chief method of attack) may be explained by a critical examination of its rationale. With regard to its function of drainage, it is not conceivable that pressure transmitted through the anterior rectal wall will have much effect on the anterior lobe of the prostate. Hence, having regard to this statement, one of the potent causes of failure may well be explained by the impossibility of adequate drainage. Again, when prostatic massage stimulates and increases the prostatic blood supply, it is contended that a prolonged course of massage may cause a coincidental mechanical irritation of the endothelium, and so bring about a flow of leucocytes by diapedesis. Thus a vicious circle may arise.

Pus-Massage $\swarrow_{\text {Drainage }}^{\text {Irritation-More Pus-Massage }} \searrow_{\text {Drainage }}^{\text {Irritation }}$ and so on. 


\section{BRITISH JOURNAL OF VENEREAL DISEASES}

I wish to emphasise that the clinical significance of a high leucocyte count in prostatic fluid is so doubtful that we are not justified in instituting treatment (based upon a method subject to criticism) which is of doubtful value to the patient. With regard to symptomatic patients, it is submitted that the benefits of treatment are obtained by virtue of its effect on a factor or factors other than the diminution of a high prostatic leucocyte count.

A discussion of these other factors is beyond the scope of the present paper, but it suffices to express the hope that present research upon the mechanism of prostatic infection will help the elucidation of present-day problems.

The practical outcome of the above is that, until further investigation has brought to light the constitution and significance of these other factors, prostates should not be treated merely because they contain high or abnormal leucocyte counts. Thus gonorrhœal patients who exhibit negative cultures, nothing abnormal in the urethra and vesicles and are otherwise asymptomatic do not require treatment.

In conclusion I quote A. Campbell : "First there is the man who, without symptoms of any kind, has pus in the expressed secretion. He gives a history of gonorrhœa some years previously; he wishes to know if he is fit for marriage. For them I prescribe prostatic massage for three months. Although most of them will still have pus at the end of that time, I think treatment is beneficial and likely to ward off later symptoms."

The above quotation, I am afraid, represents frequent grounds for present-day treatment, which are empirical and questionable as to results.

To summarise my conclusions :-

(I) In estimating the significance of a prostatitis the leucocyte count is only one factor, and an unstable factor at the most. Other factors are present of greater importance.

(2) In asymptomatic patients a high prostatic leucocyte count is not (in the light of present-day knowledge) of clinical significance, and therefore does not require treatment.

(3) Treatment, particularly prostatic massage, is of questionable value in combating the leucocyte count; and if it has value it is independent of diminishing the leucocyte count found in so-called prostatitis. 


\section{THE PROSTATIC LEUCOCYTE}

I am indebted to Dr. Anwyl Davies, Director of the London County Council (Whitechapel) Clinic for permission to quote the results obtained in the Clinic, and for his help in preparing this paper.

\section{REFERENCES}

(I) Mitchell and Von Lackum: "Chronic Prostatitis and Vesiculitis ; Physical and Microscopical Data," British Journal of Urology, September, I929.

(2) WolbaRST: "Text-book of Gonorrhœa."

(3) LuYs : " Gonorrhœa and its Complications."

(4) Surgeon-Commander Parnell: British Medical Journal, October I5th, I923.

(5) Von LACKUM : British Journal of Urology, September, I929.

(6) A. CAmpbell : British Medical Journal : October I5th, I923. 